\title{
ECONOMÍA AGROINDUSTRIAL DE CONCEPCIÓN Y EXPANSIÓN TRIGUERA FRONTERIZA: CAMPESINOS Y MAPUCHES EN BIOBÍO-MALLECO, CHILE, 1820-1850
}

\author{
AGROINDUSTRIAL ECONOMY OF CONCEPCION \\ AND WHEAT FRONTIER EXPANSION: PEASANTS AND \\ MAPUCHES IN BIOBIO-MALLECO, CHILE, 1820-1850
}

\author{
Luis Iván Inostroza Córdova \\ Universidad de la Frontera, Temuco, Chile luis.inostroza@ufrontera.cl
}

Resumen. Estudio de la formación del espacio de colonización agrícola capitalista en la frontera del río Biobío-Malleco de la Araucanía, y su articulación al enclave molinero industrial de la ciudad de Concepción mediante el transporte naviero fluvial, para dar salida a la producción triguera generada por hacendados, campesinos y mapuches, en el periodo $1820-1850$.

Palabras clave: agroindustria; capitalismo agrario; Araucanía; mapuches; campesinos.

Abstract. Study of the formation of the space of agricultural capitalist settling in the border of the river Biobio-Malleco of the Araucania, and his joint to the ready to be ground industrial enclave of Concepción's city by means of the shipping fluvial transport, to give gone out for the wheat production generated by landowners, peasants and Mapuche, in the period 1820-1850.

Key words: agroindustry; agrarian capitalism; Araucania; Mapuche; peasants.

Fecha de recepción: 25 de enero de 2014. Fecha de aceptación: 4 de junio de 2014

\section{INTRODUCCIÓN}

$\mathrm{E}$ 1 estudio de la expansión triguera capitalista, que abarca del sur de Chile hacia las tierras indígenas de la frontera del río Biobío, se ha enfocado principalmente en el periodo tardío de la ocupación de la Araucanía (Almonacid, 2009; Bauer, 1994; Bengoa, 1988, 1990; Flores, 2006; Foerster, 2008, pp. 7-35; Pinto, 2003; Robles, 2003). En tanto, las investigaciones de historia económica abordan el periodo inicial de la independencia (1810-1850) a partir de una continuidad en la estructura de la propiedad de la tierra, dominada por terratenientes vinculados al comercio exterior y en la rearticulación del comercio fronterizo con la Araucanía 
y Pampas (Carmagnani, 2001, pp. 287-298; Cavieres, 2003; Pinto, 2003, p. 47). Asimismo, se ha avanzado en el tema de la transición de una economía colonial, perteneciente al antiguo régimen, a una economía capitalista vinculada al mercado internacional después de la independencia, como un contexto general presente durante la expansión del cultivo triguero de Concepción sobre las tierras indígenas de la Araucanía (Ortega, 2005; Robles, 2003). Por otro lado, las investigaciones de historia regional han profundizado el estudio de las redes mercantiles articuladas por importantes hacendados y comerciantes asociados a las actividades de molinería, adquisición de propiedades en la frontera y el comercio con los mercados emergentes de la zona minera de Coquimbo y Copiapó. También revelaron el surgimiento de una mayor demanda de granos para los molinos industriales de la región en el periodo de 1830 a 1840 (Mazzei, 1992, pp. 217-239; 1998a, pp. 179-215; 1998b, pp. 133-186; 2004).

En este contexto historiográfico, este artículo propone emplear un enfoque multidisciplinario al conjugar perspectivas de historia económica regional, de historia fronteriza e historia del capitalismo agrario con el fin de avanzar en el estudio de factores, económicos y productivos, que moldearon la economía agroindustrial regional de Concepción, así como la expansión agrícola capitalista en la frontera del río Biobío-Malleco en la etapa de formación inicial del Estado nacional (véase mapa 1).

En primer lugar, se analiza la participación institucional de los primeros gobiernos republicanos a través de políticas económicas de expansión agrícola y de ocupación de territorios fronterizos (Cavieres, 2006, pp. 26 y 27; Pérez, 2012; Silva, 2006, pp. 224-227), las cuales se vinculan a la promulgación de una ley de adelanto de la frontera el 27 de octubre de 1823, titulada Ley de Celebración de un Parlamento General con los Araucanos y Extensión de la Línea de Frontera Sur (en adelante Ley de Colonización de 1823), y la fundación de fuertes al sur del río Biobío, entre 1834 y 1836. Ambos aspectos brindaron seguridad administrativa a las inversiones empresariales en las zonas de colonización, a través de un esquema similar a la expansión mercantil ganadera y agrícola en la frontera bonaerense, durante la transición desde la economía del antiguo régimen colonial a la economía capitalista industrial del siglo XIX (Bandieri, 2005; Banzato y Lanteri, 2007, pp. 435-458; Barcos, 2013, pp. 98-125; Garavaglia y Gelman, 2003, pp. 107-114; Míguez, Gelman y Djenderedjian, 2009, pp. 171-192). Esta fase de colonización temprana se interpreta como una colonización espontánea con débil presencia del Estado y desvinculada de los procesos mercantiles del circuito productor-exportador triguero (Leiva, 1984).

En segundo lugar, se enfatiza el desarrollo de una economía agroindustrial a escala regional, basado en el establecimiento molinero, explotación de yacimientos de carbón de piedra e instalación de una refinería de cobre 


\section{MAPA 1. FRONTERA DE CHILE Y LA ARAUCANÍA, EXPANSIÓN TRIGUERA Y TRANSPORTE FLUVIAL, 1820-1850}

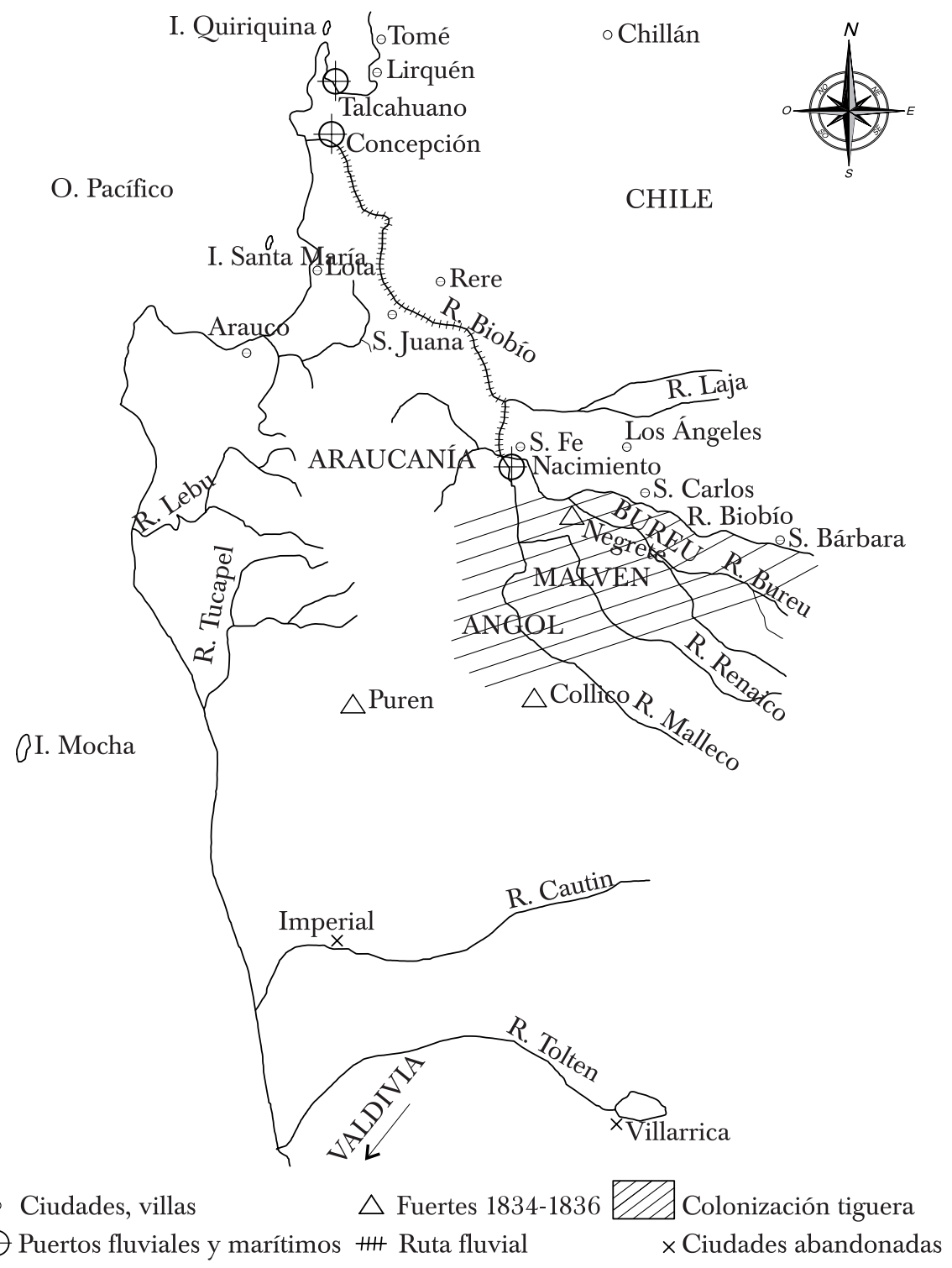

Fuente: elaboración propia. 
(Mazzei, 1992; Ortega, 2005, pp. 204-206) y talleres metalmecánicos, los cuales estaban destinados a la fabricación de herramientas, maquinarias y equipos para los procesos productivos mineros y agrícolas de la provincia de Concepción. Estas actividades transformaron la economía primaria del periodo colonial hacia una economía basada en la exportación de bienes manufacturados agrícolas, mineros, ganaderos y forestales.

En tercer lugar, se observa la presencia de innovaciones industriales en el sistema de transporte desde las áreas productivas a los centros de consumo. En este sentido, se destaca el aporte de la navegación y el cabotaje fluvial a través del río Biobío para brindar un servicio expedito y barato de comunicación comercial con el polo industrial de Concepción, lo que significó la articulación de las economías locales a los circuitos mercantiles del capitalismo, factor que impulsó las inversiones y los emprendimientos de hacendados, campesinos e indígenas en la frontera.

En el ámbito local, las políticas institucionales también incidieron en la conformación de una nueva estructura productiva, favoreciendo la expansión de haciendas dominadas por terratenientes y la progresiva participación de un segmento importante de campesinos migrantes, que ocuparon terrenos en la zona fronteriza para transformarse en productores independientes (Bauer, 1994, pp. 186-187, 191-196; Bengoa, 1988, pp. 114-118; Míguez, Gelman y Djenderedjian, 2009; Salazar, 2000, pp. 8081). Del mismo modo, los agricultores mapuches, asentados desde tiempos anteriores en los valles de la Araucanía, fueron integrados al circuito de acopio agrícola por medio de la venta de sus productos, y la unión de sus terrenos a la superficie triguera mediante arriendos y medierías de repartos de cosechas con chilenos (Inostroza, 2011).

Así, el sector productivo regional se adaptó a la demanda de cereales surgida del enclave agroindustrial y amplió la superficie de cultivos hacia las tierras mapuches al Sur del río Biobío; además, contaron con la iniciativa y los emprendimientos laborales de los nuevos agentes productivos que emergieron en el contexto de la expansión capitalista agrícola hacia la Araucanía, en el periodo de 1820-1850.

\section{POLÍTICA ECONÓMICA AGRARIA Y POLÍTICA FRONTERIZA, 1817-1836}

En la política económica de los primeros gobiernos republicanos, los hacendados y comerciantes de la provincia de Concepción influyeron mucho en sus conspicuos representantes, en particular en los directores supremos Bernardo O'Higgins (1817-1823) y Ramón Freire (1823-1826), y en los presidentes José Joaquín Prieto (1831-1840) y Manuel Bulnes (1841-1850). Desde esta posición en el gobierno nacional, establecieron políticas que 
dieron continuidad a los procesos económicos vigentes durante el periodo monárquico, promoviendo la eficiencia de los mercados regionales a través de la apertura al comercio internacional, a una mayor oferta de transporte naviero y a nuevas inversiones empresariales-industriales (Cavieres, 2006, pp. 26 y 27; Ortega, 2005, pp. 62-65; Pérez, 2012, pp. 129-151; Robles, 2003, pp. 45-80; Silva, 2006, pp. 224-227).

En la frontera del río Biobío, estas políticas se traducirían en la reorganización de las instituciones del gobierno compartido con los caciques mapuches, la articulación de las antiguas redes mercantiles entre la provincia de Concepción y los territorios indígenas (Pinto, 2003, pp. 44 y 78), y en el fomento de la ocupación productiva triguera de las tierras indígenas. De este modo, se ejecutó la aplicación de políticas públicas con el fomento de las migraciones privadas, como ocurría en la zona fronteriza pampeana (Banzato y Lanteri, 2007; D'Agostini, 2007; Barcos, 2013).

En el gobierno de Bernardo O'Higgins hubo escasos avances en materia de colonización debido al clima de inestabilidad generado por las guerras de independencia (León, 2011, pp. 53-54, y Mazzei, 2004). Al finalizar el conflicto y con la asunción de Ramón Freire a la primera magistratura en 1823, el fomento de la agricultura nacional se puso en primer plano, como estrategia para solucionar urgentes problemas sociales derivados de la guerra de independencia y la desmovilización de los contingentes que integraron los ejércitos patriotas y monarquistas. Especialmente se pretendía abordar temas como "la despoblación del país, su escasa industria, el paso lento de la civilización, la falta de aplicación al trabajo en algunos puntos, y la inmoralidad contraída en otros por el largo ejercicio de la guerra y el pillaje". ${ }^{1}$ Desde esta perspectiva, Ramón Freire presentó el proyecto de ley para adelantar la línea de frontera al río Imperial, en el cual se especifica la repartición de terrenos.

Los terrenos que yacen entre los ríos Biobío e Imperial se repartirán a discreción del gobierno en individuos que puedan dedicarse a su cultura [cultivo], prefiriendo a los indios que quieran reducirse a la vida social, y reservando lugares a propósito para el establecimiento de colonias extranjeras. Para llevar adelante esta empresa y asegurar la amistad de los araucanos, procederá el gobierno a celebrar un parlamento y consiguiente tratado (Freire, 26 de agosto de 1823). ${ }^{2}$

${ }^{1}$ Freire, R. (11 de julio de 1823). Oficio de Ramón Freire. Sesiones de los cuerpos legislativos de la República de Chile 1811-1845 (37 vols., t. VII, pp. 273-274). Santiago: Imprenta Cervantes.

${ }^{2}$ Freire, R. (26 de agosto de 1823). Proyecto de ley para adelantar línea de frontera al río Imperial. Sesiones de los cuerpos legislativos de la República de Chile 1811-1845 (37 vols., t. VIII, p. 74). Santiago: Imprenta Cervantes. 
Así, el mandatario delineaba el proyecto de integración agraria de la población campesina de Chile central, los agricultores mapuches de la Araucanía y las colonias europeas que se pensaba traer al país, para impulsar la producción agraria y el comercio exterior.

El 19 de septiembre de 1823 la Comisión de Gobierno emitió un acuerdo aprobando la iniciativa del ejecutivo. ${ }^{3}$ Después, el Congreso Nacional promulgó la Ley de Celebración de un Parlamento General con los Araucanos y Extensión de la Línea de Frontera Sur, cuyo objetivo era el repoblamiento de las ciudades de Angol, Imperial y Villarrica; en sus epígrafes estipulaba:

Artículo primero. Autorízase al gobierno para la celebración de un parlamento general con los araucanos. Art. $2^{\circ}$ Apruébase presupuesto de los 20000 pesos pedidos por el ejecutivo para celebración del parlamento y redención de las familias que existen prisioneras entre los indios, incluyéndose en aquellos la cantidad con que concurriere el gobierno de Buenos Aires según la invitación hecha. Art. $3^{\circ}$ repuéblense las ciudades de Angol, Imperial y Villarrica, sin perjuicio de asegurar, si fuere menester, la línea fronteriza al sur, como pareciere más conveniente, dando cuenta a la legislación para su sanción ${ }^{4}$ (Congreso Nacional, 27 de octubre de 1823).

Esta ley ordenaba repoblar ciudades españolas de Angol, Imperial y Villarrica abandonadas hacia 1600, proponiendo avanzar la línea fronteriza unos $300 \mathrm{~km}$ al sur del río Biobío (véase mapa 1). La promulgación de la Ley de Colonización de 1823 permitió la celebración de un tratado de paz en 1825 con el cacique Francisco Mariluán, de la comarca fronteriza subandina de Malleco, limítrofe con el partido de La Laja de la ciudad de Los Ángeles (León, 2011, pp. 116-120; Téllez et al., 2011). En esta reunión se acordó dar continuidad a las actividades de los comerciantes criollos y la repoblación de los fuertes y villas de Nacimiento, Santa Bárbara, Santa Fe y Los Ángeles, verificada a fines de $1826 .{ }^{5}$

En 1834, durante el gobierno de José Joaquín Prieto, se inició el primer avance de fuertes hacia el interior de la Araucanía, con el objetivo de reforzar una posición militar para que los indígenas "no pudiesen im-

${ }^{3}$ Congreso Nacional (19 de septiembre de 1823). Acuerdo Comisión de gobierno. Sesiones de los cuerpos legislativos de la República de Chile 1811-1845 (37 vols., t. vIII, p. 213). Santiago: Imprenta Cervantes.

${ }^{4}$ Congreso Nacional (27 de octubre de 1823). Ley de celebración de un parlamento general con los araucanos y extensión de la línea de frontera sur. Sesiones de los cuerpos legislativos de la República de Chile 1811-1845 (37 vols., t. VIII, p. 336). Santiago: Imprenta Cervantes.

${ }^{5}$ Congreso Nacional (17 de julio de 1826). Proyecto de ley enviado al ejecutivo. Sesiones de los cuerpos legislativos de la República de Chile 1811-1845 (37 vols., t. XII, p. 158). Santiago: Imprenta Cervantes. 
pedirnos en adelante el goce pacífico de los terrenos que ocupásemos" (Bustamante, 1858, t. I, p. 322). Con este objetivo, se fundaron a mediados de 1834 dos fortificaciones aproximadamente a $80 \mathrm{~km}$ al sur de la línea del río Biobío, en las comarcas de Purén y Collico (Bustamante, 1858, t. I, pp. 352 y 358-359). No obstante, la resistencia indígena obligó el repliegue de las guarniciones el 5 de enero de 1835 (El Araucano, 30 de enero de 1835, núm. 229, pp. 3-4). Por su parte, el general Manuel Bulnes ordenó en 1836 la construcción del fuerte de Negrete en las márgenes del río Bureu para fortalecer la posición del avance al sur del río Biobío, de esta manera se establecía una guarnición de apoyo administrativo a la colonización de hacendados y campesinos en la zona; más adelante, este fuerte se convirtió en el símbolo de la expansión estatal sobre los territorios indígenas fronterizos.

Por otro lado, la política fronteriza también estaba condicionada por sucesos internacionales que afectaban la seguridad del nuevo Estado. En particular las exportaciones trigueras y harineras a Perú fueron gravadas con nuevos impuestos a comienzos de la década de 1830; mientras, la creación de la Confederación Perú-Boliviana, por el general boliviano Andrés de Santa Cruz, amenazaba la supremacía del puerto de Valparaíso en el comercio internacional del Pacífico sur. El conflicto económico originaría la invasión de Perú por el ejército chileno a través de dos expediciones, una en 1836 y la otra en 1837. La primera expedición no tuvo resultados concretos, y la segunda, comandada por el general Bulnes, derrocó al mandatario de la confederación y con ello se restablecieron los privilegios trigueros del comercio nacional (Basadre, 2002, pp. 25-42; Ortega, 2005, pp. 58-59), además de consolidarse la proyección de la expansión triguera en la zona fronteriza.

\section{CAMPESinos nacionales EN LA FRONTERA DEL Biobío}

La Ley de Colonización de 1823 constituyó un soporte institucional de notable significación jurídica, brindando seguridad administrativa a las inversiones de los grandes hacendados y comerciantes que adquirieron algunas propiedades en las décadas de 1830 y 1840 (Cerda, 1996, p. 117; Mazzei, 1998a, pp. 148-150). La compraventa, el arriendo, la donación, y la hipoteca de terrenos indígenas se incrementaron a partir de la década de 1850, con un auge en las décadas de 1860 y 1870 (Foerster, 2008, p. 12). No obstante, la influencia principal de dicha ley era evidente en el flujo de inmigrantes campesinos de Chile central, que encontraron terrenos en los vastos espacios de la frontera, donde se asentaron para organizar unidades de producción trigueras articuladas al circuito mercantil capitalista (Bauer, 
1994, pp. 186-187 y 191-196; Bengoa, 1988, pp. 114-118; Banzato y Lanteri, 2007, pp. 435-458, y Míguez, Gelman y Djenderedjian, 2009, pp. 171-192; Salazar, 2000, pp. 108-111).

El acceso relativamente fácil a la ocupación de tierras agrícolas en la frontera mediante la posesión de terrenos baldíos y el arriendo a indígenas, favoreció la formación de enclaves agrícolas campesinos. El estadunidense Rehuel Smith, durante su visita a la Araucanía en 1852, describe un típico asentamiento campesino en el valle del río Bureu, que permite reconocer algunas características de este segmento productor fronterizo:

Algunas seis u ocho millas más allá del Biobío, llegamos a Budeo [Bureu], reunión de media docena de ranchos ocupados por chilenos, quienes como Sánchez arrendaban y cultivaban tierras pertenecientes a los indios. Mi guía poseía una casa en San Carlos, donde generalmente residía; pero en ese momento la familia se encontraba en Budeo, donde lo ayudaban en la cosecha de trigo. [...] Una legua más allá llegamos a Malven, cerca del cual viven esparcidos un gran número de cristianos (Smith, 1914, pp. 70 y 95).

Se reconoce la figura de Pantaleón Sánchez como un capitán de amigos, es decir, un funcionario del gobierno fronterizo de la intendencia de Concepción para los asuntos indígenas. Su residencia habitual estaba en la villa de San Carlos, cerca de Los Ángeles. También poseía una residencia y terrenos de siembras en la zona ultrabiobío que trabajaba con el aporte del trabajo familiar, arrendados a los indígenas.

En la zona fronteriza se repetían los enclaves campesinos chilenos, según informaba el prefecto de Misiones, apuntando que el asentamiento de Malven:

se hallaba a seis leguas al sur de Negrete y doce de Nacimiento, es centro de tres parcialidades bastante numerosas, teniendo al sur a menos de una legua el distrito del cacique Carina con unas cuarenta poblaciones de indios; al norte a igual distancia el del cacique Huaiquivilo con trescientas poblaciones de infieles y más de cincuenta indios de Santa Fe (así llamados por haber dejado sus estancias y el vasto potrero de este nombre), al levante al otro lado del río Bureu tiene el partido del cacique Llupai con unas veinticinco poblaciones de infieles y más de ochenta indios santafinos; hay también en estas parcialidades varias casas de españoles, de las cuales como cincuenta se encuentran en el mismo punto de Malven. ${ }^{6}$

${ }^{6}$ Fray Diego de Chuffa (15 de septiembre 1852). Memoria sobre las misiones de la provincia de Concepción (Archivo Ministerio del Interior, vol. 278). Archivo Nacional, Santiago, Chile. 
En otros documentos misionales se informaba del número de colonos en este lugar: "Malven, este punto es de la mayor importancia. Las colinas de Malven y los contornos de la arruinada Colhue estaban habitadas por seiscientos sesenta y seis españoles, dispuestos a abandonar sus ranchos, tan luego como se fuera el misionero." 7

El número de 600 españoles, nombre dado a los chilenos en la frontera, ilustra la magnitud de la inmigración campesina y de las unidades de producción articuladas al comercio provincial. Sobre el avance de la colonización triguera en la zona del río Bureu, en 1856 se indicaba:

Hay en estos territorios bodegas de depósitos y hermosas fincas que premian los esfuerzos de sus dueños con abundantes cosechas. El espacio comprendido entre el Bureu y el Biobío, merced a las fáciles comunicaciones para la exportación y a la fecundidad increíble de su suelo, se halla convertido en una colonia de labradores, cuyas producciones no tardarán con competir con las del resto de la provincia (Ruiz, 1856, p. 260). ${ }^{8}$

Junto a las fincas de los grandes comerciantes, Ruiz Aldea enfatiza la presencia de una colonia de labradores. Aludiendo de este modo a los emprendimientos agrícolas del segmento campesino. El informe citado relevaba la alta producción local indicando que en Bureu:

La agricultura se desarrolla admirablemente en el territorio de que doy cuenta. Por regulación prudente se puede calcular en cinco mil fanegas de trigo las sementeras que se cultivan en el presente año. El producido que se espera en razón de ser preparados en terrenos vírgenes y de superior calidad, no bajará de cien mil fanegas; esto es reduciendo el cálculo a una escala muy inferior de lo que ordinariamente sucede (Ruiz, 1856, p. 260).

Respecto a la inmigración ascendente de campesinos en la frontera, el intendente de Concepción indicaba en 1846 que al abrigo del fuerte de Negrete "se ha ido reuniendo una población de cuarenta a cincuenta casas de paja, que se ha erigido en subdelegación y que recibe sus auxilios espirituales del curato de Nacimiento". ${ }^{9}$ En 1853 se indicaba un crecimiento ascendente de esta localidad con 103 casas y 1000 habitantes (El Correo

\footnotetext{
${ }^{7}$ Fray Antonio Gavillucci (8 de mayo de 1855). Informe de la viceprefectura de Misiones, Chillán (Archivo Ministerio del Interior, vol. 278). Archivo Nacional, Santiago, Chile.

${ }^{8}$ Cursivas del autor. Este trabajo fue impreso más tarde como Pedro Ruiz Aldea, La provincia de Arauco, Imprenta el Meteoro, Los Ángeles, 1863, sin una nota editorial explicativa de su reedición, y con la impresión tipográfica de 1863.

${ }_{9}^{9}$ Memoria del Intendente de Concepción, 1846 (Archivo Ministerio del Interior, vol. 196). Archivo Nacional, Santiago, Chile.
} 
del Sur, enero de 1853, núm. 133, p. 2). Ese mismo año se indicaba que la población rural del distrito era de 4199 habitantes para Nacimiento y de 2451 habitantes en Negrete. ${ }^{10}$

La creación de la subdelegación de Negrete conformaba otro apoyo institucional a las actividades de colonización, además de ejercer un control más directo sobre las actividades de los chilenos en el territorio fronterizo, cuyo número aumentaba constantemente como señal de la importancia demográfica de este nuevo segmento de productores agrícolas en la frontera de la Araucanía. Fenómeno concomitante a la expansión fronteriza del capitalismo agrario en las fronteras surandinas de Chile y Argentina.

En cuanto al funcionamiento de las unidades productivas campesinas, debemos puntualizar el empleo de sistemas laborales asociativos y cooperativos entre las familias agricultoras, conocidos en la frontera y Chile central como mingacos, donde el gasto en dinero era casi nulo, pues se pagaba el trabajo con comidas, chicha y vino; así, el trabajo agrícola se desenvolvía en un ambiente festivo de cooperación en cada una de las posesiones agrícolas de las familias participantes (Bauer, 1994, p. 173).

Con estos terrenos extensos y tal fuerza laboral asociativa, los campesinos contribuían con su iniciativa y trabajo a mejorar sus condiciones de vida, además de incrementar los acopios trigueros demandados por la economía regional. Del mismo modo, la población campesina constituía un voluminoso sustrato laboral para el funcionamiento de las haciendas y conformaba un factor productivo abundante y barato en el ámbito local.

\section{PRODUCTORES MAPUCHES}

Las poblaciones indígenas de la frontera de Angol y Malleco también se integraron al circuito mercantil de cereal por medio del cultivo de trigo y su comercialización en las villas fronterizas de Santa Juana, Nacimiento, Negrete y Santa Bárbara.

Ignacio Domeyko, en un informe sobre las actividades económicas de chilenos y mapuches -que denomina araucanos, según la tradición etnográfica oficial- elaborado durante su viaje a la Araucanía en 1845, describe las unidades de producción agroganaderas indígenas:

El araucano es agricultor por su carácter, por la naturaleza física de su país, por su genio y sus costumbres. [...] El pacífico araucano tiene su casa bien hecha,

${ }^{10}$ Carta del intendente de la provincia de Arauco al director de la Oficina de Estadística (1 de septiembre de 1854) (Archivo Intendencia de Arauco, vol. 6). Archivo Nacional, Santiago, Chile. Véase Leiva, 1984, p. 206. 
grande, espaciosa de veinte y más varas de largo y de ocho a diez de ancho, bien abrigada contra los vientos y las lluvias, alta, construida con buena madera, coligüe y paja, con una sola entrada y un agujero puesto en lo alto del techo para la salida del humo. Inmediato a su casa tiene huertas y sementeras de trigo, cebada, maíz, garbanzos, papas, linaza, repollos; todo bien cultivado y cercado y como las habitaciones se hallan por lo común en la vecindad de algún río o estero, en sus contornos se divisan las lindas campiñas y floridas praderías, en que el indio tiene sus caballos y su ganado gordo, hermoso, aunque no tan numeroso como el de los hacendados chilenos (Domeyko, 1846, pp. 51-52).

La descripción de Domeyko delinea la producción agroganadera indígena, organizada junto al núcleo residencial doméstico con campos de cultivo y campiñas de pastoreo ganadero. En cuanto a la tecnología agrícola indígena, Claudio Gay (1998) observó en 1863 la importancia del uso de yuntas de bueyes y arados, al señalar que "los hombres aran la tierra y siembran el trigo, las mujeres cuidan el cultivo, luego son los hombres los que lo cosechan y las mujeres lo limpian" (p. 60). En otro punto, Gay agrega: "el arado de los indios es muy simple, es como el de los chilenos del sur, compuesto de la punta unida al timón por medio de la espiga. Esta punta tendrá una vara de largo. La mansera o brazo que se sostiene con la mano tiene también como máximo una vara y según lo estime el labrador" (pp. 104-105).

Otra tecnología vinculada al desarrollo agrícola mapuche fue el trillar con yeguas, en correspondencia a la mayor extensión de siembras indígenas. Rehuel Smith en 1852 apuntaba que en Chochol, cerca del río Cautín, encontró "una treintena de personas, hombres, mujeres y niños ocupados en trillar el trigo. El método empleado era el de trillar con yeguas a la usanza chilena. Media docena de jinetes estaban en la era, empapados en sudor, cubiertos de tierra y gritando a toda fuerza de pulmones" (p. 207).

Con las tecnologías occidentales del antiguo régimen, las familias mapuches desarrollaron prácticas agrícolas significativas en sus modos de vida y como actividad proveedora de excedentes comercializables en el mercado indígena y capitalista (Inostroza, 2011), situación que favoreció las relaciones mercantiles entre los agricultores indígenas y las redes del comercio capitalista.

Antonio Varas, comisionado por el Congreso Nacional para emitir un informe sobre las transacciones mercantiles de criollos y mapuche en la frontera de la provincia de Concepción, caracterizó aspectos del control de estas actividades apuntando: "En el día estas prescripciones no son observadas, y el indígena sale a los pueblos vecinos de la frontera, hace su comercio sin la menor traba, consultando sus intereses en sus transacciones hasta con impertinencia" (Varas, 1849, p. 17). Respecto al intercambio 
mercantil Varas observó: "El comercio les ha hecho dedicarse algo más a la crianza de animales y siembra de granos; ha excitado su actividad. Ya trabaja algo más de lo que las necesidades de un indio exigen; ya desea proporcionarse las comodidades que el español goza, ya gusta de vestirse de los mismos tejidos, y se empeña en adquirir con qué comprarlos" (Varas, 1849 , p. 17). En esta perspectiva, subrayó las compras anticipadas de siembras preponderantes en la incorporación de la producción indígena a las redes de acopio cerealero de Concepción: "La buena fe del indígena en estos casos es generalmente reconocida, y sin más garantía que su palabra se hacen compras anticipadas de cosechas y de animales" (Varas, 1849, p. 23).

La producción familiar y las explotaciones privadas se complementaban con otros emprendimientos asociativos, llevados a cabo con campesinos chilenos para realizar siembras y repartir cosechas. En esta línea, el viajero Rehuel Smith (1914) consignaba: "Nos acompañó parte del viaje, un chileno que trabajaba por cuenta de un vecino indio, recibiendo en recompensa de su labor en cultivar terrenos, cierto porcentaje de los productos" (p. 152).

La articulación mercantil de la economía indígena comprendía la inserción de propietarios mapuches en la dinámica empresarial del capitalismo agrícola al seguir diversas fórmulas. $\mathrm{Al}$ respecto, el periodista de Los Ángeles, Pedro Ruiz Aldea, escribió:

El estado de la agricultura prospera muy rápidamente. Pasado el Biobío, se sorprende uno al ver los campos cubiertos de tupidos bosques de espigas, rebaños de animales, de poblaciones cristianas. Convencido de la utilidad que reportan, el indio no pone impedimento para estos trabajos, permite que se conduzcan ganados por su territorio, i he oído a un cacique decir querer asociarse a un comerciante de Los Ángeles para fabricar un molino en las corrientes del Bureu (Ruiz, 1856, p. 260).

Más adelante, el mismo autor subraya la articulación de la economía mapuche al auge comercial capitalista: "Comparado el estado naciente de la agricultura con el que teníamos atrás, notamos que en estos últimos tiempos ha recibido un impulso superior. Indios y españoles no piensan más que en las siembras, ${ }^{11}$ plantación de viñas y crianzas de ganados, que son los tres ramos que constituyen el comercio principal de la frontera (Ruiz, 1856, p. 260).

Respecto al volumen de productos extraídos desde Nacimiento y previsiblemente producidos por indígenas, se apuntaba en 1856 las siguientes

${ }^{11}$ Cursivas del autor. 
cifras: "25000 fanegas de trigo. 15000 animales vacunos. 5000 quintales de lana. Los artículos de consumo son. Prendas de plata. Camisas. Chaquiras. Añil. Pañuelos. Casacas etc.” (Ruiz, 1856, p. 257). Además, el comercio indígena involucraba otras villas donde se canalizaba el intercambio: "En el departamento de Santa Juana, se avaluaba su comercio con los indios en 50000 pesos. Igual o menores sumas deben representar los pueblos de Arauco, Santa Bárbara, Antuco, Los Ángeles” (Ruiz, 1856, p. 257).

De acuerdo con estos datos el comercio fronterizo mapuche pudo alcanzar un valor global de 200000 pesos anuales hacia 1850. Una estimación del valor de las transacciones fronterizas en 1860 sugiere un aumento progresivo del intercambio que se elevó en esta fecha a 300000 pesos (Morales, 1860, p. 412; Pinto, 2003, p. 163), mientras en la frontera bonaerense, el valor del tráfico fronterizo se estimaba en 500000 para 1862 (Vezub, 2005).

Las cifras apuntadas permiten dimensionar un importante volumen de productos agrícolas comercializados por los indígenas, fenómeno vinculado a una reorientación del comercio de textiles y ganado del siglo XVIII, hacia el cultivo triguero durante el siglo XIX que reemplaza los tejidos para complementarse estrechamente con el tráfico ganadero (Pinto, 2000). En este escenario es relevante subrayar el desempeño de los mercaderes mapuches que transportaban los bienes producidos en el territorio indígena hacia los centros de acopio occidentales, lo cual muestra una adaptación dinámica a las nuevas condiciones del mercado capitalista que se instalaba en los bordes del dominio indígena.

El tráfico fronterizo también tiene otras repercusiones en el ámbito de la economía indígena, principalmente a través de la acumulación de riqueza suntuaria mediante la recepción de monedas de plata chilena como pago de bienes agropecuarios.

Respecto al volumen de plata que circulaba desde los mercaderes chilenos hacia los productores indígenas, una referencia consignada por Smith ilustra esta cuestión: "Si suponemos que trafican con los indios, dos a tres mil personas y estimamos que cada uno de ellos dispone anualmente de veinte o treinta pesos en monedas de plata, se puede ver fácilmente la considerable dificultad que causa la sustracción de esta cantidad de circulación de una zona no muy poblada ni rica" (Smith, 1914, p. 96 ).

En cuanto a la magnitud de la población indígena de la Araucanía, desde el río Biobío al río Toltén, no contamos con datos de la década de 1850; sin embargo, un recuento de 1870 entrega una matrícula de 18096 "hombres de lanza", que representaron un volumen global de 90480 habitantes mapuche. En la zona fronteriza del Arauco los hombres de armas se computaban en 1000 , para representar 5000 habitantes. En la zona de Biobío y Malleco sumaban 6914 con una población total de 34570 per- 
sonas ("Informe sobre el territorio de Arauco", 1998, pp. 128-133). Estas cifras ayudan a visualizar el impacto de la población indígena en la conformación del mercado fronterizo.

La circulación de monedas de plata hacia el territorio indígena pudo ascender a un monto de 60000 a 210000 pesos anuales; cifra que grafica la magnitud de la acumulación metálica por medio del comercio fronterizo y la integración al mercado capitalista de los agricultores mapuche. En este sentido, el viajero Smith contrastó el modo de vida rústico del cacique Mañil de Collico con los magníficos arreos ecuestres del jefe indígena: "Sin embargo me fijé que colgada de la ramada había una brida, con freno, cabezada y riendas, cubiertas de adornos de plata maciza, y aunque Mañín se consideraba pobre, doscientos pesos fuertes no habrían pagado todo el metal que vi en los aperos que usaba para montar a caballo" (Smith, 1914, p. 161). En otro lugar, Smith señalaba: "Además de los frenos, estribos, jaquimones y aperos de plata, los indios usan zarcillo, prendedores y otros adornos del mismo metal, que es el único que ellos emplean para fines ornamentales" (Smith, 1914, pp. 93 y 95).

Es evidente que se percibe un flujo de doble entrada en el comercio fronterizo indígena de mediados del siglo XIX. Tanto la venta de la producción triguera al mercado agrícola de Concepción, como la acumulación de piezas de plata provenientes del comercio chileno, dan cuenta de la articulación dinámica de la economía agraria indígena a los circuitos mercantiles de la economía capitalista mediante una estrategia de larga duración en la historia regional del sur de Chile.

\section{Tráfico Fluvial de Nacimiento a ConcePción}

Uno de los elementos más destacados en la expansión triguera fronteriza fue la instauración de un sistema de transporte fluvial, de donde se enviaba la producción de Los Ángeles, Malleco, Bureu y Malven hacia los centros molineros de la ciudad de Concepción, como alternativa al tráfico terrestre de mulas y carretas por tortuosos caminos.

En 1843, un artículo periodístico informaba del tráfico de cabotaje fluvial desde Nacimiento hasta Concepción. Respecto de la villa de Nacimiento se indicaba que tenía una posición comercial ventajosa: "teniendo al margen el río Biobío donde trafican en el día treinta lanchas que conducen a Concepción todos los productos de la frontera" (El Telégrafo de Concepción, Chile, 11 de marzo de 1843, p. 2).

La navegación se extendía hacia los afluentes tributarios del Biobío, en particular a través del río Malleco: "cuyo curso se dirige de sur a norte siendo navegable en lanchas hasta más de 14 leguas al interior de las po- 
sesiones indígenas" (Charme, 1858, p. 233). La ruta fluvial del río Malleco conectaba una zona de $77 \mathrm{~km}$ situada en los renombrados llanos trigueros de Angol, que se extendían desde el pie de las serranías de Nahuelbuta hacia las tierras precordilleranas del río Bureu.

En los años siguientes aumentó progresivamente el número de lanchas dedicadas al tráfico mercantil. En 1854, el intendente de Concepción indicaba que en la jurisdicción marítima de la provincia existían "150 a 200 lanchas planas, que sin salir del Biobío, Vergara y Laja hacen sólo el comercio interior, sin jamás tocar los puertos por donde se exportan los frutos que conducen y que depositan a las inmediaciones de esta ciudad, para trasladarlos en otra clase de vehículos" (Sotomayor, 1854, p. 194).

La Sociedad Nacional de Agricultura publicó en 1856 un estudio sobre la vida económica en la zona de Los Ángeles y Malleco, destacando la función mercantil de Nacimiento y del cabotaje fluvial:

Nacimiento. Está en el ángulo que forma la confluencia Vergara (Malleco) con el Biobío, en los $37^{\circ} 17^{\prime} 30^{\prime \prime}$. Esta circunstancia le da a Nacimiento la vista más pintoresca de Chile; sólo Santa Bárbara que se halla al pie de una hermosa colina podría disputársela; pero Nacimiento le lleva la ventaja por estar cerca del sitio en que vienen a atracar las lanchas de Concepción. A esto se debe la importancia agrícola y comercial que en él se desarrolla en el día. Lo he llamado el Valparaíso de la frontera, porque es el depósito de todos los productos indígenas y el que atrae mayor número de inmigrantes por el interés del negocio (Ruiz, 1856, pp. 250-251). ${ }^{12}$

El apelativo de "Valparaíso de la frontera" revela la importancia del puerto fluvial de Nacimiento para el desarrollo mercantil del espacio de colonización. Sobre todo porque el cabotaje facilitaba el comercio de importación y exportación, y entregaba un medio de transporte expedito y de bajo costo. De acuerdo con las tarifas del cabotaje recopiladas por Claudio Gay en 1863, el costo era el siguiente: "El transporte de Los Ángeles al Biobío un real la fanega para bodegaje un real, flete de lancha hasta Concepción dos reales y de allí a Talcahuano un real en todo cinco reales" (Gay, 1998, p. 52).

Este cálculo que tiene como base la ciudad de Los Ángeles, puede extrapolarse a las remesas salidas de Angol, Malven y Bureu para ilustrar la influencia del tráfico de lanchas en la expansión de la producción triguera capitalista hacia el territorio indígena, ofreciendo un medio de transporte expedito y de bajo costo para los emprendimientos productivos de campesinos y agricultores mapuches.

${ }^{12}$ Cursivas del autor. 


\section{DEMANDA MOLINERA Y EXPORTACIÓN AGRÍCOLA E INDUSTRIAL}

El dinamismo observado en la frontera del Biobío por la expansión triguera se conectaba con la nueva demanda de insumos de la industria molinera, instalada en la región en las décadas de 1830 y 1840 (véase cuadro 1). El despegue de la molinería fue facilitado por el acceso a una abundante producción triguera regional aportada por campesinos e indígenas de la provincia y la zona fronteriza. Situación que permitía a los molineros obtener cada fanega ${ }^{13}$ de trigo puesta en las bodegas de Tomé a un costo de doce reales (Mazzei, 1998a, p. 198).

Respecto al valor de la fanega de trigo en el mercado local, su bajo precio se relacionaba con los pequeños gastos que efectivamente se realizaban en las haciendas y asentamientos campesinos, al emplearse el sistema de trabajo cooperativo del mingaco. No obstante, en el ámbito de la organización de las haciendas donde predominaba el trabajo de jornaleros asalariados, los antecedentes reunidos por Claudio Gay permitieron identificar la permanencia de costos muy reducidos de las operaciones productivas agrícolas. En sus notas de viaje en la frontera de Los Ángeles, el científico francés apuntaba en 1863:

Para romper una cuadra de tierra donde los bueyes cuestan dos pesos y doce reales para cruzar, con buenos bueyes un peón lo hace en cuatro días. Un peón bota cinco a seis fanegas al día y un buen peón tapa de cuatro a cinco almudes al día y siendo malo sólo tres.

La tarea de 35 varas de largo y 25 de ancho se paga a tres reales. Se hace ordinariamente una tarea al día y un muy buen segador una tarea y media; con frecuencia trabajan de noche.

Una cuadrilla de seis hombres hace doce carretadas al día, cada carretada de tres a cuatro fanegas.

Una era de mil fanegas se trilla en seis o siete días con 100 yeguas y de 30 a 40 peones. Se paga para este trabajo 100 pesos. Ordinariamente se paga de tres pesos y medio a cuatro pesos para aventar y limpiar 100 fanegas. Para llevar el trigo de la era al granero que es a distancia de 30 cuadras importa cada fanega dos centavos con la comida.

Sin meter en cuenta tierra y los bueyes cada fanega le ha salido de seis a ocho reales la fanega (Gay, 1998, pp. 51-53).

\footnotetext{
${ }^{13}$ Fanega: medida de peso del periodo colonial equivalente a 82 kilos.
} 
CUADRO 1. MOLINOS EN CONCEPCIÓN, CHILE, 1830-1848

\begin{tabular}{|c|c|c|}
\hline Empresarios molineros & Lugar & Fecha instalación \\
\hline Fundador Olof Ligilvach & Molino de Puchacay & 1830 \\
\hline Sociedad con Enrique Burdon & & 1835 \\
\hline Adquirido por Ignacio Palma & & 1839 \\
\hline Fundador Tomás Waldford & Molino Lirquén & 1836 \\
\hline $\begin{array}{l}\text { Sociedad Enrique Rogers } \\
\text { y Samuel Haviland }\end{array}$ & Molino Santo Domingo & 1845 \\
\hline $\begin{array}{l}\text { Sociedad Olof Ligilvach, Guillermo } \\
\text { Gibson y Pablo Délano H. }\end{array}$ & Molino Tomé & 1837 \\
\hline Sociedad Délano Gibson y Cía. & & 1839 \\
\hline $\begin{array}{l}\text { Sociedad Guillermo Gibson Délano } \\
\text { y Tomás Kingston Sanders }\end{array}$ & Molino Tomé & 1843 \\
\hline $\begin{array}{l}\text { Sociedad Guillermo Gibson Délano } \\
\text { y Tomás Kingston Sanders }\end{array}$ & $\begin{array}{l}\text { Molino Bellavista } \\
\text { de Coelemu }\end{array}$ & 1843 \\
\hline Antonio Meye & Molino en Penco & 1844 \\
\hline $\begin{array}{l}\text { Sociedad Juan Gillmoere } \\
\text { y Santiago Evans }\end{array}$ & $\begin{array}{l}\text { Molino Landa } \\
\text { en Lirquén }\end{array}$ & 1846 \\
\hline $\begin{array}{l}\text { Sociedad Francisco Urrejola } \\
\text { y Ramón Cruz }\end{array}$ & $\begin{array}{l}\text { Molino en Tomé } \\
\text { "California" }\end{array}$ & $\begin{array}{l}1848 \\
1851\end{array}$ \\
\hline
\end{tabular}

Fuentes: elaboración propia con base en Cerda (1996, pp. 108-119) y Mazzei (1992, p. 222, y 1998a, p. 192).

Tomando la referencia del gasto de ocho reales por fanega y el valor de cinco reales de conducción fluvial a Talcahuano, el hacendado realizaba una inversión de doce reales, en un periodo que el valor de la fanega era de tres pesos, es decir, 24 reales. De esta manera, el bajo costo de los factores productivos conformó una variable significativa en la rentabilidad de la producción de hacendados, campesinos e indígenas en la frontera. No obstante, debemos advertir que los datos de salarios deben considerase como referencias en un esquema general de contabilidad de la renta agrí- 
cola, porque en la práctica tanto hacendados como campesinos incurrían en gastos muy moderados, ya que contaban con mano de obra propia o contratada mediante fórmulas asociativas de reparto de cosechas, regalías y primicias (Bauer, 1994, pp. 173-174). En este sentido, los cálculos del gasto en las haciendas deben considerarse en relación con un momento puntual de la expansión productiva agrícola, y aunque no contamos por el momento con series de precios y salarios de este periodo, sí es posible advertir que estos altos niveles de ganancia se mantuvieron en las décadas siguientes, vinculados al auge de la exportación harinera hacia California, Australia, Argentina e Inglaterra y a la intensificación de la ocupación de Araucanía en el periodo de 1852 a 1883.

Los molinos industriales influyeron en la transformación de la economía regional, después de la independencia, sobre las exportaciones de trigo y de harinas por el puerto de Talcahuano en 1846 (véase cuadro 2). Estas cifras representan un testimonio claro de la transformación agroindustrial en Concepción y su economía provincial, orientada en este periodo a las exportaciones de harinas. Cabe aclarar que las cifras presentadas corresponden a una etapa previa al auge de la exportación al mercado de California, que se inició en 1849, y sobre todo en 1850.

Respecto a la última fase del periodo colonial, el descenso de las exportaciones a Perú pasó de 69000 fanegas por 90000 pesos, en 1808, a 12565 fanegas por 45000 pesos en 1846 (Carmagnani, 2001, p. 141). En contraste, desde una perspectiva comparativa las exportaciones trigueras de Chile en 1846 alcanzaron un volumen de 86356 fanegas por 256000 pesos; por lo tanto, el grano de Concepción representaba sólo $14 \%$ del comercio chileno, mientras las exportaciones correspondía en su mayor parte a los embarques salidos desde los puertos de Talcahuano y Tomé (Bauer, 1994, p. 89).

Asimismo, en 1846 el grano fue reemplazado por remesas de harinas elaboradas en la región con 99020 fanegas por un valor de 638318 pesos; estas cifras ilustran el impacto progresivo de la consolidación de la economía agroindustrial en la región de Concepción después de la independencia. Desde esta perspectiva agroindustrial debemos señalar el crecimiento ascendente de los molinos hacia 1852 (véase cuadro 3).

La cifra total de 842000 quintales, equivalente a 421000 fanegas, de capacidad anual de elaboración de harina, muestra el nivel de la demanda molinera para la agricultura regional. La producción de granos en la provincia alcanzaba las 220000 y 267000 fanegas de trigo anuales (Anónimo, 1857a, p. 169), por lo cual previsiblemente el resto de los insumos provenía de las tierras fronterizas de Malleco y Bureu. Por otro lado, para ilustrar el consumo de los establecimientos industriales, apuntaremos que el molino California, en un inventario de 1851, registraba 10000 fanegas 


\section{CUADRO 2. EXPORTACIONES DE TRIGO Y HARINA TALCAHUANO, CHILE, 1846}

\begin{tabular}{lcc}
\hline Producto & Fanegas & Valor en pesos \\
& & \\
Harina & 99020 & 638318 \\
Trigo & 12565 & 45317 \\
\hline
\end{tabular}

Fuente: elaboración propia con base en Estadística comercial de la república de Chile. Correspondiente al año 1846 (1848, pp. 19, 35, 52, 68, 83 y 85). Valparaíso: Imprenta Europea.

CUADRO 3. MOLINOS PROVINCIA DE CONCEPCIÓN, CHILE, 1852

\begin{tabular}{lcccc}
\hline Departamento & $\begin{array}{c}\text { Molino } \\
\text { de vapor }\end{array}$ & $\begin{array}{c}\text { Molino } \\
\text { común }\end{array}$ & $\begin{array}{c}\text { Fuerza } \\
\text { quintales diarios }\end{array}$ & $\begin{array}{c}\text { Harina flor } \\
\text { quintales anuales }\end{array}$ \\
Concepción & 1 & - & 80 & 18000 \\
Coelemu & 14 & - & 5000 & 800000 \\
Puchacay & 4 & - & 800 & 24000 \\
Rere & - & 25 & - & - \\
Lautaro & 2 & 7 & 600 & - \\
Total & 21 & 32 & 640 & 000 \\
\hline
\end{tabular}

Fuente: elaboración propia con base en Anónimo (1857a, p. 178).

de trigo como reserva en bodega para su elaboración (Mazzei, 1998a, pp. 194-195).

El intendente de Concepción enfatizaba la escasez relativa de granos que comenzaba a incidir en los costos de compra debido al aumento de los molinos, razón por la que se inició un segundo ciclo de instalación molinera en la zona interior de la provincia para asegurar la provisión de insumos y rentabilizar las inversiones empresariales; al respecto, la autoridad escribió en 1854:

De los 53 molinos, nueve de primera clase se encuentran establecidos en los puertos y los demás se separan para el interior, buscando el depósito del trigo, que escasea ya para tantos establecimientos, porque fuera de los enumerados hay de primera clase dos en Chillán y otros dos en Los Ángeles, que retienen mucha parte de las abundantes cosechas, que se obtienen en esos Departamentos. Esa competencia obra también favorablemente, en el precio y en la vida que toman todos 
los campos capaces de producir y que poco ha estaban abandonados (Anónimo, 1857a, p. 179).

De esta forma, se comprueba el efecto multiplicador de la industria molinera sobre la actividad triguera regional por medio de una demanda superlativa que incentivó las iniciativas empresariales agrícolas de hacendados y transportistas fluviales, así como los emprendimientos productivos campesinos y la articulación de los productores mapuches al circuito de acopios cerealeros de los molinos instalados en la región.

\section{Exportaciones agroindustriales de Concepción, 1846}

En términos de volumen físico y valor del comercio exterior en el puerto de Talcahuano en 1846, la producción molinera de harina representó cerca de 50\% de las exportaciones. También es significativo el rubro de vino y aguardiente asociado a una importante actividad vitivinícola regional. Las remesas agrícolas conformaban el principal rubro del cabotaje con la zona minera de los puertos de Coquimbo, Huasco y Copiapó, donde se enviaban alimentos por un costo de 197640 pesos, constituyéndose uno de los principales focos del comercio agrícola regional de Concepción (Mazzei, 1998b, pp. 154-155; Pinto y Ortega, 1991) (véase cuadro 4).

En segundo lugar aparecen las exportaciones ganaderas con suelas de cueros de vacunos para la industria del calzado, carne salada para consumo mediato, chaños, tejidos de lana de oveja y cabríos elaborados en la ciudad de Chillán y en la Araucanía. Destacan en estos embarques, por su alto valor, las remesas de lana dirigidas principalmente a Estados Unidos.

La exportación de madera constituía un rubro antiguo en la economía regional con 170000 piezas y un valor de 51793 pesos; representaba el mayor volumen físico de las exportaciones.

El sector económico de mayor importancia fue el minero, ya que estuvo asociado a la transformación industrial de la economía regional después de la independencia. El valor de la exportación de carbón en 1846 por 39884 pesos refleja una significativa renta, aunque subvalorada respecto al combustible utilizado en las faenas fabriles regionales; en tanto, entre 1844 y 1850 se exportaron 25000 toneladas de carbón mineral (Ortega, 2005, p. 204). Las actividades extractivas en los célebres yacimientos de Coronel y Lota, en 1854, reunían 900 individuos distribuidos en 38 minas y piques (Anónimo, 1857a, p. 174); de esta manera se representaba una importante concentración laboral y un relevante foco de consumo de alimentos para la agroindustria regional. 
CUADRO 4. EXPORTACIONES, PUERTO DE TALCAHUANO, 1846

\begin{tabular}{lcr}
\hline Producto & Volumen & Precio en pesos \\
Harina & 99020 fanegas & \\
Trigo & 12565 fanegas & 638318 \\
Papas & 1112 fanegas & 45317 \\
Vino & 9727 arrobas & 3060 \\
Aguardiente & 1572 arrobas & 26691 \\
Lana & 13480 quintales & 9964 \\
Suelas & 12387 unidades & 94232 \\
Carne salada & 2356 quintales & 29512 \\
Cueros & 6504 unidades & 13365 \\
Chaños & 1229 unidades & 8664 \\
Madera & 170309 piezas & 1923 \\
Cobre en barra & 4201 quintales & 51793 \\
Carbón de piedra & 103000 quintales & 57353 \\
& & 39884 \\
\hline
\end{tabular}

Fuente: elaboración propia con base en Estadística comercial de la república de Chile. Correspondiente al año 1846 (1848, pp. 19, 35, 52, 68, 83 y 85). Valparaíso: Imprenta Europea.

El enclave industrial minero y portuario de Concepción se completó con la instalación, en 1846, por parte del empresario Joaquín Edwards, de la refinería de cobre en Lirquén (Ortega, 2005, pp. 187-205 y 206; Venegas, 2008), que en ese año registró una exportación de cobre refinado de 4201 quintales por 57353 pesos, ocupando así el tercer lugar del valor de los embarques portuarios.

La actividad de la fundición se extendió a otras áreas metalmecánicas de fabricación de instrumental como alambiques y lagares para la vitivinicultura, y equipamientos que sirvieron para las actividades mineras, los astilleros, el crecimiento urbano de la ciudad de Concepción, y, sobre todo, la expansión agrícola regional.

En un informe de la provincia de Nuble, que se había desmembrado del territorio provincial de Concepción en 1849, se indicaba que sólo se utilizaban artefactos de elaboración local: "conociéndose apenas los arados y rastras de marca Ramírez", agregando que instrumentos modernos similares a los importados "se fabricaban en la fundición establecida en Concepción por la firma comercial Perron y Ca." (Anónimo, 1857b).

Respecto a esta empresa metalmecánica, se apuntaba que "había fabricado cuatro máquinas para trillar tirada por bueyes, con harneador incluido y capacidad de doce fanegas por hora, vendidas por $\$ 700$ cada 
una" (Miquel, 1856, p. 401). En un ensayo sobre las minas de carbón de Coronel se indicaba adicionalmente que en estos fundidores mecánicos "estaban construyéndose maquinas a vapor adecuadas al uso de estos minerales" (Anónimo, 1857c). La fabricación de herramientas y maquinarias muestra el desarrollo agroindustrial alcanzado por la economía regional y el impacto de estas innovaciones en la expansión triguera fronteriza.

\section{CONCLUSIONES}

El apoyo institucional del Estado, mediante el dictado de la Ley de Colonización de 1823, y la fundación de nuevos fuertes fronterizos entre 1834 y 1836, se conjugó con el establecimiento de molinos industriales en Concepción para impulsar la expansión de la superficie cultivada triguera hacia los territorios mapuches situados al sur del río Biobío. Así se inauguró un proceso de colonización con la presencia de hacendados y, sobre todo, de un importante segmento de campesinos, instalados en la frontera como productores independientes conectados al circuito de acopios trigueros articulado por la demanda agroindustrial de los molinos de Concepción.

Además, la expansión capitalista también integró la producción agrícola de las comunidades mapuches como un nuevo rubro del intercambio fronterizo indígena de ganados mayores y lana de ovejas. Se articularon las tierras productivas de las comunidades a la superficie de cultivo triguero agroindustrial mediante arriendos y medierías de repartos de cosechas, de campesinos y hacendados con los agricultores mapuches. Mecanismos que se utilizaban en el ámbito del tráfico ganadero y que se trasladan al tema del cultivo de la tierra mediante asociaciones mercantiles con los propietarios indígenas.

La proliferación de estos intercambios generó un activo e importante comercio indígena en las villas fronterizas de Santa Juana, Nacimiento, Santa Bárbara y Los Ángeles, y una articulación temprana de los indígenas al mercado capitalista agroindustrial. Además, esta complementariedad económica contribuyó al surgimiento de una estructura de productores formada por hacendados, campesinos y mapuches, que caracterizaron el espacio rural de la Araucanía de los siglos XIX y XX

Por otra parte, el servicio de cabotaje a través del río Biobío aportó un medio de transporte barato y expedito que facilitó la salida de la producción agrícola fronteriza de Angol, Malvén y Bureu, mediante su embarque hacia Concepción en el puerto fluvial de la villa de Nacimiento.

La organización de este sistema de transporte de carga se vinculaba con un proceso mayor de intensa industrialización en la provincia de Concepción. En efecto, junto a la instalación de molinos, se desarrollaron sig- 
nificativas inversiones de capitales en faenas mineras carboníferas en la costa de Arauco, construcción de refinerías de cobre en Lirquén, equipamientos portuario en Talcahuano y Tomé con astilleros para la fabricación y reparación de embarcaciones y navíos, y establecimientos balleneros, entre otros.

Estas actividades imprimieron un dinamismo a la demanda de insumos trigueros de los molinos y su producción harinera destinada al creciente mercado de alimentos reasentado por el aumento del consumo a escala provincial, en las faenas mineras de Copiapó y Coquimbo, y en los mercados de Perú, Argentina, Europa y Estados Unidos. Destinos principales de la exportación agroindustrial de Concepción en la década de 1840.

\section{Fuentes CONSUltadas}

\section{Lista de referencias}

Almonacid, F. (2009). El problema de la propiedad de la tierra en el sur de Chile. Historia, 42(1), 5-56.

ANÓNImo (1857a). La agricultura en la provincia de Concepción en 1854. En El Mensajero de la Agricultura. Boletín Mensual de la Sociedad Nacional de Agricultura (t. II, p. 178). Santiago: Imprenta Chilena.

Anónimo (1857b). Informe de la Provincia de Nuble. En El Mensajero de la Agricultura. Boletín Mensual de la Sociedad Nacional de Agricultura (t. II). Santiago: Imprenta Chilena.

AnÓnimo (1857c). Minas de Coronel en 1857. En El Mensajero de la Agricultura. Boletín Mensual de la Sociedad Nacional de Agricultura (t. II). Santiago: Imprenta Chilena.

BANDIERI, S. (2005). Del discurso poblador a la praxis latifundista, la distribución de la tierra pública en la Patagonia. Mundo Agrario. Revista de Estudios Rurales, 6(11). Recuperado de http://www.mundoagrario.unlp.edu.ar/article/view/v06n11a01/1288

BANZATO, G. y LANTERI, S. (2007). Forjando la frontera. Políticas públicas y estrategias privadas en el río de la Plata, 1780-1860. Historia Agraria. Revista de Agricultura e Historia Rural, 43, 435-458.

BARCos, M. F. (2013). Los derechos de propiedad ejidal en el contexto desamortizador iberoamericano. La campaña de Buenos Aires, siglo XIX. América Latina en la Historia Económica, 20(1), 98-125.

BASADRE, J. (2002). La iniciación de la república, contribución al estudio de la evolución política y social del Perú. Lima: Universidad Nacional Mayor de San Marcos. Recuperado de http.//sisbib,unmsm,edu,pe/bibvirtual/libros/historia/iniciacion_republica/tomo2 /Lib2_Cap6_1,htm 
BAUER, A. (1994). La sociedad rural chilena desde la colonia a nuestros días. Santiago: Andrés Bello.

BengOA, J. (1988). Historia social de la agricultura chilena. El poder y la subordinación(t. I). Santiago: Ediciones Sur.

Bengoa, J. (1990). Historia social de la agricultura chilena. Haciendas y campesinos (t. II). Santiago: Ediciones Sur.

Bustamante. F. J. (1858). Memoria que el ministro de Estado de Guerra y Marina presenta al Congreso Nacional, año 1835. En Discursos de apertura en las sesiones del Congreso i memorias ministeriales correspondientes a la administración Prieto, 1831-1841 (t. I, pp. 311-329). Santiago: El Ferrocarril.

Carmagnani, M. (2001). Los mecanismos de la vida económica en una sociedad colonial, Chile 1680-1830. Chile: Dirección de Bibliotecas, Archivos y Museos.

CaVieres, E. (2003). Servir al soberano sin detrimento del vasallo. El comercio hispano colonial y el sector mercantil de Santiago de Chile en el s. XVIII. Valparaíso: Ediciones Universitarias de Valparaíso.

CaVieres, E. (ed.) (2006). Entre continuidades y cambios las América en la transición (s. XVIII a XIX). Valparaíso: Universidad Católica de Valparaíso.

Cerda, P. (1996). Fronteras del sur. La región del Bío-Bío y la Araucanía chilena 1604-1883. Temuco: Universidad de La Frontera.

Charme, A. (1858). Observaciones generales sobre las vías de comunicación en Chile, 1853. En Discursos de apertura en las sesiones del Congreso i memorias ministeriales en los dos primeros años del primer quinquenio de la administración Montt, 1852-1853 (t. IV, pp. 224-235). Santiago: El Ferrocarril.

D’Agostini, V. A. (2007). Enfiteutas, propietarios, agregados y ocupantes en el "nuevo sur", los partidos de Arenales y Ayacucho (1823-1860). Mundo Agrario. Revista de Estudios Rurales, 7(14). Recuperado de www.mundoagrario.unlp.edu.ar

Domeyko, I. (1846). Araucanía i sus habitantes. Santiago: Imprenta Cervantes.

FLORES, J. (2006). Economías locales y mercado regional, 1883-1935. Espacio Regional, 2(3), 11-28.

Foerster, R. (2008). Los procesos de constitución de la propiedad en la frontera norte de la Araucanía: sus efectos esperados y no esperados en el imaginario y en la estructura de poder. Cuadernos de Historia, 28, 7-35.

Garavaglia, J. C. y Gelman, J. (2003). Capitalismo agrario en la frontera, Buenos Aires y la región pampeana en el siglo XIX. Historia Agraria. Revista de Agricultura e Historia Rural, 29, 105-121.

GAY, C. (1998). Viaje a la Araucanía en 1863. En I. InOsTroZA (ed.), Etnografía mapuche del siglo XIX (pp. 45-104). Santiago: Dirección de Bibliotecas, Archivos y Museos.

Informe sobre el territorio de Arauco y la población indígena 1868-1869 (1998). En I. InOSTROZA (ed.), Etnografía mapuche del siglo XIX (pp. 107-135). Santiago: Dirección de Bibliotecas, Archivos y Museos.

InOSTROZA, I. (2011). El concepto de la propiedad de la tierra en la tradición mapuche. Revista de Educación y Humanidades, 1(2), 101-133. 
LeIva, A. (1984). El primer avance a la Araucanía, Angol 1862. Temuco: Universidad de la Frontera.

LEÓN, L. (2011). O’Higgins y la cuestión mapuche, 1817-1818. Santiago: Akilleus.

MAZzeI, L. (1992). Orígenes del establecimiento británico en la región de Concepción y su inserción en la molinería del trigo y en la minería del carbón. Historia, 28, 217-239.

Mazzei, L. (1998a). Terratenientes de Concepción en el proceso de modernización de la economía regional, en el siglo XIX. Historia, 31, 179-215.

MAZzei, L. (1998b). Trayectorias empresariales en Concepción en el siglo XIX. El caso de José Ignacio Palma Barriga. En J. PinTo (ed.), Modernización, inmigración y mundo indígena. Chile y la Araucanía en el siglo XIX (pp. 133-186). Temuco: Universidad de La Frontera.

MAZzeI, L. (2004). La red familiar de los Urrejola de Concepción en el siglo XIX. Chile: Dirección de Bibliotecas, Archivos y Museos.

Míguez, E., Gelman, J. y Djenderedjian, J. (2009). La agricultura pampeana en la primera mitad del siglo XIX, Buenos Aires, siglo XXI. Boletín de Historia Argentina y Americana Dr. Emilio Ravignani, 31, 171-192.

MiQuel, M. (1856). Datos estadísticos sobre la exportación de los productos agrícolas de Chile. En El Mensajero de la Agricultura. Boletín Mensual de la Sociedad Nacional de Agricultura (t. I). Santiago: Imprenta Chilena.

Morales, J. C. (1860). Indicaciones sobre la reducción de indígenas y colonización de la Araucanía. En Revista del Pacífico (t. IV). Santiago: El Mercurio.

Ortega, L. (2005). Chile en ruta al capitalismo. Cambio, euforia y depresión. 1850-1880. Chile: Dirección de Bibliotecas, Archivos y Museos.

Pérez, C. (2012). La configuración del espacio económico en el marco de la construcción del Estado, el oriente salvadoreño, 1840-1855. Revista Complutense de Historia de América, 38, 129-151.

Pinto, J. (2000). Producción e intercambio en un espacio fronterizo Araucanía y Pampas en el siglo XVIII. En J. Silva y A. Escobar, Mercados indígenas en México, Chile y Argentina. Siglos XVIII-XIX. México: Instituto de Investigaciones Dr. José María Luis Mora/Centro de Investigaciones y Estudios Superiores en Antropología Social.

Pinto, J. (2003). La organización del Estado y la nación y el pueblo mapuche. Chile: Dirección de Bibliotecas, Archivos y Museos.

Pinto, J. y ORTEGA, L. (1991). Expansión minera y desarrollo industrial, un caso de crecimiento asociado (Chile 1850-1914). Santiago: Universidad de Santiago.

Robles, C. (2003). Expansión y transformación de la agricultura en una economía exportadora. La transición al capitalismo agrario en Chile (1850-1930). Historia Agraria. Revista de Agricultura e Historia Rural, 29, 45-80.

Ruiz, A. P. (1856). Provincia de Arauco. En El Mensajero de la Agricultura. Boletín Mensual de la Sociedad Nacional de Agricultura (t. I). Santiago: Imprenta Chilena.

SAlAzAr, G. (2000). Labradores, peones y proletarios. Santiago: LOM Ediciones. 
Sesiones de los cuerpos legislativos de la República de Chile 1811-1845 (1886-1908). (37 vols., tt. VII, VIII, XII). Santiago: Imprenta Cervantes.

Silva, J. (2006). Del mercado colonial de la Nueva España a la economía nacional del siglo XIX. En E. CaVieres (ed.), Entre continuidades y cambios las América en la transición (s. XVIII a XIX) (pp. 223-249). Valparaíso: Universidad Católica de Valparaíso.

SMith, E. R. (1914). Los araucanos o notas sobre una gira efectuada entre las tribus indígenas de Chile Meridional. Santiago, Imprenta Universitaria.

Sotomayor, R. (1854). Informe del Intendente de Concepción sobre puertos. En Discursos de apertura en las sesiones del Congreso i memorias ministeriales en los tres últimos años del primer quinquenio de la administración Montt, 1854-1856 (t. v.). Santiago: El Ferrocarril.

Téllez, E., Silva, O., Carrier, A., y Rojas. V. (2011). El tratado de Tapihue entre ciertos linajes mapuches y el gobierno de Chile [edición facsimilar de 1825]. Cuadernos de Historia, 35, 169-190.

VARAS, A. (1849). Informe presentado a la Cámara de Diputados por el visitador judicial de la república en cumplimiento del acuerdo celebrado en la sesión de 20 de diciembre del año pasado. Santiago: Julio Bein y Compañía.

Venegas, H. (2008). El carbón de Lota. Textos y fotografías del siglo XIX. Las visiones de Francisco Marcial Aracena y Guillermo E. Raby. Santiago: Pehuén.

Vezub, J. (2005). Redes comerciales del país de las manzanas. A propósito del pensamiento estructural de Guillermo Madrazo. Revista Andes, 16, 167-198. 